of life, that training is not the same as long experience. The questions linked to the current CME series were not deemed of sufficient quality for publication and have therefore been omitted for which we apologise. Potential solutions to this dilemma include setting questions in the specialty which are not directly related to the specific contributions or attracting the help of experienced question setters. Other constructive suggestions would be welcome.

\title{
A call to action
}

\author{
Steven Weinberger, Eric Holmboe, Michael Cheshire and Jane Ingham
}

Despite remarkable medical and technical advances in healthcare, there is evidence that delivery and quality of care are below the highest standards. ${ }^{1,2}$

Leaders from the American Board of Internal Medicine (ABIM), the American College of Physicians (ACP) and the Royal College of Physicians (RCP) in the UK, with experts from the disciplines of quality and safety, met in September 2009 to discuss the challenges of improving quality of healthcare in both countries.

Participants agreed on common areas of challenge:

- the need for greater transparency of information for the public about the performance of health services

- urgent attention to healthcare costs and the efficient use of resources

- renewed attention to helping individuals stay well

- the promotion of healthy populations

- system alignment, especially between financial incentives and professional standards and values

- quality improvement as a core value of professionalism in order to motivate and drive progress ${ }^{3,4}$

- greater involvement of physicians in interdisciplinary teamwork. ${ }^{5}$

A Call to action was discussed with leaders of medical societies from around the world during an International Forum held at the ACP's annual meeting in Toronto in April 2010. Society leaders from 17 additional countries spread over six continents expressed interest in joining a multinational effort focused on improving quality of care.

Four areas in need of urgent attention were identified:

1 physician leadership ${ }^{6}$

Steven Weinberger, executive vice president and chief executive officer, American College of Physicians; Eric Holmboe, chief medical officer and senior vice president, American Board of Internal Medicine; Michael Cheshire, clinical vice president (2007-10), Royal College of Physicians (RCP), London; Jane Ingham, director, Clinical Standards, $\mathrm{RCP}$, London
2 effective engagement with patients

3 interdisciplinary teams

4 measuring performance., ${ }^{4,7}$

Physicians are a positive force for change and as part of the commitment to the Call to action, the ABIM, ACP and RCP will collaborate to advance change throughout a physician's career from medical school through clinical practice, and over the next year develop a programme of work to support this commitment based upon shared learning, dissemination of tools and resources and collaboration on quality improvement projects. Finally, we will work to engage medical organisations from other nations to broaden this effort into a worldwide initiative.

\section{References}

1 McGlynn EA, Asch SM, Adams J et al. The quality of health care delivered to adults in the United States. N Engl J Med. 2003;348;2635-45.

2 Institute of Medicine. Crossing the quality chasm: a new health system for the 21st century. Washington: National Academy Press, 2001.

3 General Medical Council UK. Good medical practice. London: GMC, 2006. Available at: www.gmc-uk.org/static/documents/content/ GMC_GMP_0911.pdf

4 ABIM Foundation, ACP-ASIM Foundation, European Federation of Internal Medicine. Medical professionalism in the new millennium: a physician charter. Ann Intern Med 2002;136:243-6

5 Institute of Medicine. Health professions education: a bridge to quality. Washington: National Academy Press, 2003.

6 Thomson O'Brien MA, Oxman AD, Haynes RB et al. Local opinion leaders: effects on professional practice and health care outcomes. Cochrane Database Syst Rev 2000;(2):CD000125.

7 Landon BE, Normand S-L T. Performance measurement in the small office practice; challenges and potential solutions. Ann Intern Med 2008;148:353-7.

Address for correspondence: J Ingham, Clinical Standards Department, Royal College of Physicians, 11 St Andrews Place, Regent's Park, London NW1 4LE.

Email: jane.ingham@rcplondon.ac.uk 